\title{
Adriana Santos Delgado y Hugues Sánchez Mejía. La irrupción del capitalismo agrario en el Valle del Cauca: politicas esta- tales, trabajo y tecnología, 1900-1950, Universidad del Valle: Cali, 2010.
}

El estudio acerca de las transformaciones agrícolas en nuestro país tiene una deuda historiográfica y aunque si bien es cierto existen estudios que abordan esta temática, falta mucho por explorar. Este factor ha permitido que en los últimos años la irrupción del capitalismo en las zonas agrarias como objeto de estudio se haya convertido en un tema de interés para los historiadores.

El texto de los investigadores Adriana Santos y Hugues Sánchez se centra en la citada temática. El escrito tiene como objetivo principal observar las modificaciones agrícolas que se vivieron en el hoy departamento del Valle del Cauca desde finales del siglo XIX hasta la primera mitad del siglo $\mathrm{XX}$. Es un estudio minucioso de ardua indagación, que permite a los autores hacer un microanálisis del mencionado departamento, describiendo los múltiples elementos que intervinieron en el desarrollo económico que tuvo el mismo.

El texto está dividido en cinco partes. En la primera de ellas se hace mención al contexto socioeconómico del Valle del Cauca, haciendo énfasis en dos variables primordiales para la investigación sobre el avance del capitalismo en el sector agrario durante el siglo XX: “1) Reconocer los vínculos regionales y nacionales con dinámicas globales, como la expansión del capitalismo a nivel mundial. 2) Es necesario partir de la premisa que defiende la existencia de rasgos propios a la hora de mirar los desarrollos del merca- 
do en escenarios concretos"1. Por lo tanto, primero no podemos aislarnos de los procesos que se están produciendo a nivel internacional como fue el caso de la llamada "revolución verde", ya que su impacto no solo tuvo repercusiones en la adecuada mecanización de la agricultura, la perfección de los fertilizantes, aumento de la población en territorio europeo, sino también en el latinoamericano y colombiano y segundo, es importante hacer énfasis que internamente se dieron cambios que permiten comprender la vinculación de Colombia a un mercado mundial a través del incremento de la producción agrícola.

Así, el Valle del Cauca al iniciar el siglo XX se caracterizaba generalmente por utilizar la mayor cantidad de tierras para la actividad económica ganadera a la que "(...) por excelencia se dedicaban las familias notables de la región, seguida por el cultivo de cacao". No obstante el panorama experimentó un cambio radical donde se pasó de la actividad ganadera a la agraria en un mayor porcentaje.

Esta última, se convirtió en el motor del desarrollo económico de un espacio que no reflejaba un ambiente muy halagador desde mediados y finales del siglo XIX, debido a “(...) vías atrasadas, escasez de población, atraso en los sistemas de producción, anulación del crédito interno, alto interés del dinero, agio y especulación, desmoralización, pereza y deseos de vivir a expensas ajenas"3. Esas fueron algunas de las causas que conllevaron a que el desarrollo del sector agrario fuera una posible solución para salir de un constante deterioro socioeconómico, donde la caña de azúcar y el café terminaron siendo los productos líderes de este proceso de cambio.

En la segunda parte se expone la intervención del Estado y la participación de la élite local, que se terminó formando por las diversas acciones estatales que brindaban grandes oportunidades de invertir y recibir beneficios. De manera que se fue articulando una clase dominante directamente asociada con el poder estatal, donde la tierra y su uso intensivo se convirtieron

1 Adriana Santos Delgado y Hugues Sánchez Mejía, La irrupción del capitalismo agrario en el Valle del Cauca: políticas estatales, trabajo y tecnología, 1900-1950 (Cali: Universidad del Valle, 2010), 8.

2 Adriana Santos Delgado y Hugues Sánchez Mejía, La irrupción del capitalismo agrario, 13.

3 Adriana Santos Delgado y Hugues Sánchez Mejía, La irrupción del capitalismo agrario, 12. 
en el centro del desarrollo económico local. La tierra se terminó volviendo un bien codiciado por muchos, pero en manos de pocos. Santos y Sánchez señalan que para la élite local, un elemento decisivo, fue la creación de una unidad político/administrativa que les diera autonomía, representara sus intereses y les permitiera avanzar hacia la consolidación de una clase dominante de alcance regional. Fue así, que las élites vallecaucanas promulgaron a principios del siglo XX la creación de un nuevo departamento y con ello, se abrió un espacio institucional desde el cual, propenderían por el desarrollo de su proyecto económico de modernización.

En síntesis el Estado, al igual que la élite local se relacionaban por intereses socioeconómicos encontrados que finalmente contribuyeron a que el Valle del Cauca se constituyera en una importante zona del país durante la primera mitad del siglo XX.

El segundo capítulo se subdivide en dos ítems, en el primero se plasma el papel que cumplió el Estado, por ejemplo en la inversión de infraestructura del tren del Pacífico, uno de los importantes proyectos viales de la época. Que logra evidenciar el primer punto de engarce entre los intereses regionales y los del Estado. Conectando gran parte del país en un “(..) proceso de integración del mercado interno de las zonas productoras de café, tabaco, cacao y caña de azúcar - con sus derivados-y, posteriormente, de este con el mercado internacional"4. En el segundo ítem se hace mención del papel del departamento del Valle del Cauca mediante la creación de instituciones que incentivaban el desarrollo económico a través del sector agrícola de dicha ciudad, estableciendo al mismo tiempo políticas que garantizaban participación de todos los habitantes bajo la premisa de aprovechar la fertilidad de la tierra ${ }^{5}$.

En el tercer capítulo, los autores se encargan de mostrarnos cómo actores concretos incidieron en el desarrollo local. Así, se hace alusión a Carlos Durán Castro, agrónomo que visitó los Estados Unidos de América y trajo consigo el modelo norteamericano de apoyo estatal al crecimiento del campo. Presentando descripciones de las llamadas estaciones experi-

4 Adriana Santos Delgado y Hugues Sánchez Mejía, La irrupción del capitalismo agrario, 21

5 Adriana Santos Delgado y Hugues Sánchez Mejía, La irrupción del capitalismo agrario, 27-28. 
mentales; un ejemplo que prueba la construcción de estas en el Valle es la creación de la Experimental de Palmira -institución que incidió en el desarrollo de la región-. El otro individuo que se logra identificar, es el Secretario General de Industrias del departamento del Valle Ciro Molina Garcés, actor a quien “(...) Castro Durán presentó el documento con los resultados de sus observaciones en el viaje realizado a los Estados Unidos. Fue él mismo quien convirtió el contenido de dicho informe en sustento de las acciones emprendidas, durante la década del 30, en el sector agropecuario del Valle del Cauca y de todo el país" ". En definitiva estos actores son pieza clave en el avance tecnológico y económico de la ciudad.

La cuarta parte se encuentra dividida internamente en dos ítems, primero se manifiesta el problema que se presentó en el Valle del Cauca acerca de los derechos de propiedad de la tierra y cómo el proceso de modernización agrícola que se estaba llevando a cabo en el departamento implicaba una rápida solución para la expansión de los ingenios-unidad productiva. El segundo ítem presenta una problemática que no solo afectó al Valle del Cauca en específico, ya que otras regiones también pasaron por esa dificultad, que es la escasez de mano de obra. En este caso se hacía imprescindible una gran cantidad de brazos para emprender correctamente y eficientemente las actividades agrícolas. Llegándose a implementar diversas estrategias para mantener la mano de obra; un ejemplo es el de la hacienda La Manuelita, donde permitieron que los llamados terrazgueros se ubicaran en los bordes de la hacienda, cultivan y a la vez vendían su mano de obra de manera estacionaria ${ }^{7}$.

En la última parte, los autores también la dividen en dos ítems. En el primero se corrobora el proceso del cultivo de la caña y la producción de azúcar, convirtiéndose en el sector líder de la transformación agroindustrial del Valle del Cauca -pasando del trapiche al ingenio azucarero- acotando la responsabilidad de este proceso a diversos factores: 1) el mejoramiento y la dotación de las vías de comunicación y la adaptación de tecnología al cultivo de la caña; 2) el papel jugado por las alianzas de familia en el des-

6 Adriana Santos Delgado y Hugues Sánchez Mejía, La irrupción del capitalismo agrario, 45.

7 Adriana Santos Delgado y Hugues Sánchez Mejía, La irrupción del capitalismo agrario, 70. 
pegue de la industria a finales de la década del $20^{8}$ y, 3) la crisis de la producción de azúcar vivida en Cuba durante la década del veinte. El segundo ítem, alude al desarrollo de la producción del cultivo del café en el Valle del Cauca y cómo este terminó posicionándose.

En conclusión, este libro es de gran utilidad para tener mejor entendimiento sobre el proceso de desarrollo del sector agrario en el Valle del Cauca mediante la irrupción del capitalismo y los diversos factores que lo estimularon. Sin olvidar que este documento es el inicio de un arduo trabajo, que tal indican Santos y Sánchez requerirá de otras investigaciones para una mayor profundización.

\section{Eva SANDrín García Charris}

Estudiante de Historia, Universidad del Atlántico (Colombia) gevasandrin@hotmail.com 